\title{
IDENTIFICATION AND CHARACTERIZATION OF NEUTRAL PROTEASE PRODUCING Paenibacillus Polymyxa SPECIES EMBS024 BY 16S rRNA GENE SEQUENCING
}

\author{
ANURAJ N.S..$^{*}$, SHEAZA AHMED ${ }^{1}$, MUKESH YADAV ${ }^{1}$, SNEHA SINGH², MEER ASIF A. ${ }^{2}$, MAYURA MAYNAL ${ }^{3}$ \\ AND URVASHI PISAL ${ }^{2}$
}

\author{
1/n Silico Research Laboratory, Eminent Biosciences, Vijaynagar, Indore-452010, MP, India. \\ 2Department of Biotechnology, Softvision College, Indore-452010, MP, India. \\ ${ }^{3}$ Dept. of Health and Bioscience, University of East London, UK. \\ *Corresponding Author: Email- anuraj@eminentbio.com
}

Received: June 22, 2012; Accepted: June 28, 2012

\begin{abstract}
The term probiotics means supporting life, just being on the opposite spectrum to antibiotic which is against life. Probiotic microorganisms are those microbially derived factors that stimulate the growth of other microorganisms. They are considered to be the best alternative of antibiotics. The current study illustrate the identification of a neutral protease producing bacteria from soil by 16s rRNA sequencing technique. The sample was collected from outskirts of Vijayawada, Andhra Pradesh, India, over dump food wastes soil. The collected sample was serially diluted and the targeted colony after incubation over a certain time period was introduced to 16s rRNA sequencing. The result showed the extract to be a neutral protease producing bacteria which was further named as Paenibacillus polymyxa strain EMBS024. After characterization the sequence of isolate was deposited in GenBank with accession number JQ004091.
\end{abstract}

Key words- 16s rRNA sequencing, Paenibacillus polymyxa strain EMBS024, neutral protease producing probiotics.

Citation: Anuraj N.S., et al. (2012) Identification and Characterization of Neutral Protease Producing Paenibacillus Polymyxa Species EMBS024 by 16 S rRNA Gene Sequencing. International Journal of Microbiology Research, ISSN: 0975-5276 \& E-ISSN:0975-9174, Volume 4, Issue 5, pp.-236-239.

Copyright: Copyright@2012 Anuraj N.S., et al. This is an open-access article distributed under the terms of the Creative Commons Attribution License, which permits unrestricted use, distribution, and reproduction in any medium, provided the original author and source are credited.

\section{Introduction}

Etymologically the term probiotic is comprised of the Latin preposition pro ("for") and the Greek adjective biotic, the latter being derived from a noun bios which means 'life' [1]. The use of probiotic microorganisms is an alternative to the use of antibiotics in increasing microbial infections, in both humans and man. So it is a good point of research in its application in farming and agriculture. Fuller gave a stable definition of probiotics as "A live microbial feed supplement which beneficially affects the host animal by improving its intestinal microbial balance" [2]. The major concept and knowledge of probiotics came into existence in early 2000. A vital clinical study published in 2001 suggested that one of the probiotic strain had a preventive effect against allergic diseases [3]. Much information from animal or in vitro models suggests that probiotics protect against the development of Colon tumors [4]. While probiotics have long been popular in Europe and Japan, these friendly bacteria are just now making it to North America in food products and dietary supplements. The two main types of bacteria considered to be probiotics include strains from the Lactobacillus and Bifidobacterium genera. Some probiotics have been shown in preliminary research to possibly treat various forms of gastroenteritis [5]. A 2007 study at University College Cork in Ireland showed that a diet including milk fermented with Lactobacillus bacteria prevented Salmonella infection in pigs [6]. Probiotics are also used as prophylactic agents as well as therapeutic agents. Probiotics not only are good bacteria essential for healthy digestion, there is more and more research showing that good bacteria can help fight 'lifestyle' diseases like obesity, tooth decay, and heart diseases. Most attempts to propose probiotics have been undertaken by isolating and selecting strains from aquatic environment.

Paenibacillus polymyxa is a gram-positive, facultative anaerobic, endospore-forming bacteria capable of fixing nitrogen, so is used in agriculture and horticulture. It also promotes plant growth and suppresses plant diseases, also called as plant growth promoting rhizobacterium (PGPR). Along with acting as a plant growth pro- 
moting rhizobacterium, and as a controlling agent of soil borne plant diseases [7] it has been involved in various functions. This includes the formation of biofilm i.e. colonization of plant roots by PGPR which enhances the plant growth rate along with the production of metabolites, antibodies, and nutrient uptake [8]. The antibiotics (polymyxin, paenbacillin:a lantibiotic, proteinaceous in nature) produced by one of the strain of Paenibacillus polymyxa has been shown as acting against a broad range of food spoilage bacteria along with the physio chemical properties that includes water solubility, thermal resistance and stability against acid and alkali [9]. The antibiotic activity aids in providing immunity to the host plant from various pathogen [10]. The Paenibacillus polymyxa has also made its notification in the field of various enzyme activity such as the xyloglucanase activity by degrading the polysaccharides present in plants (cell wall) which has helped in smoothing many processes in textile as well as in detergent industries and the biomass conversion of biofuel [11]. The anticoagulant and fibronolytic enzyme activity has its application in its respective field [12]. The antimicrobial activity i.e. the antagonistic behavior of Paenibacillus polymyxa against a wide spectrum of organisms (Escherichia coli RR1, Pseudomonas Xuorescens R73, Pantoea agglomerans BC1, Butyrivibrio Wbrisolvens OR85, and Fibrobacter succinogenes ATCC 19169)is notable and has open gates in terms of food and medical application [13].

\section{Proteases}

Proteases also termed as peptidases or proteinases are the proteolytic enzymes mainly focused in the metabolism of proteins. Proteases can be acidic, basic and neutral depending upon the optimal $\mathrm{pH}$ in which they show maximum activity. Alkaline proteases of microbial origin has been useful in various fields including tannery and food industries, medicinal formulations, detergents and processes like waste treatment, silver recovery and resolution of amino acid mixtures [14]. The acidic proteases producing bacteria are helpful in the form of probiots. Neutral proteases has been used in tissue culture technique, separation of intact epidermis from dermis and intact epithelial sheet in culture from the substratum (Kurt et al. 1989) harvest and transfer of normal, diploid cells and cell lines (Matsumura et. al 1975) gentle and intact detachment of epidermal cells (Kitano and Okada 1983).

\section{Neutral Proteases}

Neutral protease is a $\mathrm{Zn}$-metalloendopeptidase that is produced by Paenibacillus polymyxa. Although related to trypsin, neutral protease has been found less harmful to cells and has its application in preventing unwanted cell clumping without cell membrane damage after one hour incubations (Alvarez et al. 2006).It has been studied that the neutral protease, dispase, isolated from Bacillus polymyxa is found to be a rapid, effective and gentle agent for separating intact epidermis from the dermis [15] which can be used later for many cosmetic and clinical applications. The dispase bacterial neutral protease from Bacillus polymyxa also detaches posterior vitreous and may be used in removing cortical vitreous during vitreous surgery [16].

\section{6s rRNA Gene Sequencing}

The practice of assigning scientific names to various identified microbial species is one of the most important practice of microbi- ologists for the intent of spreading awareness and knowledge regarding the pathological and useful aspects of these organisms respectively [17]. Accurate identification of bacterial species is an essential task of clinical microbiology laboratory. The identification can be done mostly in two ways, namely the ancient way by examining the phenotypic relation of the discovered strain with the already available strains and by genotypic identification, such as small subunit 16s rRNA gene sequencing [18]. The wide use of 16s rRNA gene sequencing for examining the bacterial phlogeny and taxonomy is because of following three reasons; (i) it is present in all forms of bacteria as a multigene family or operon; (ii) the function of these has remain conserved i.e. has not changed; (iii)the 16s rRNA gene length (approximately 1,500 bp) is large enough for it to be used for informatics studies [19]. The prokaryotic 16s rRNA gene codes for the small subunit of ribosome as it is well known that ribosome has two subunits large and small. This 16s rRNA gene is a part of prokaryotic DNA which is present in all bacteria and is highly conserved, for this reason it is used for phylogenetic studies.

\section{Sample Collection and its Storage}

The sample was collected from outskirts of Vijayawada over dump food wastes soil. The actual site was surveyed before. The sample was collected from five sites 1 feet below the ground, as for the good reason that moisture condition is good for bacteria to survive under 1 feet and surface will never have the probability to get bacteria. So the chance of getting our probiotic is good below 1 feet. Five samples were collected in five zip lock packets to prevent the entry of any other microbe in it. These packets were then put for refrigeration at $4^{\circ} \mathrm{C}$ to stop the bacteria metabolism temporarily.

\section{Sample Mixing and Serial Dilution}

$1 \mathrm{gm}$ each from those five zip lock packets was taken and was mixed together and then was grounded until fine particles were obtained. From this $5 \mathrm{gm}, 1 \mathrm{gm}$ was taken and was dissolved and mixed in $100 \mathrm{ml}$ of distilled water. This mixing can be done in many ways like magnetic method, handmade shakers etc. This sample is ready for serial dilution which involves the further described steps. Serial dilution is performed on the Laminar Air Flow platform. Six test tubes were taken containing $9 \mathrm{ml}$ distilled water. $1 \mathrm{ml}$ solution was taken from that mixed $100 \mathrm{ml}$ suspension and then transferred to the first test tube. The $10^{-5}$ and $10^{-6}$ dilution tubes after incubation yielded sufficient number of colonies. The important thing to note is the test tubes used should be autoclaved under standard conditions. By serial dilution we can know about colony forming units of bacterial isolates from the soil sample. We should get the single isolated bacterial colonies on our petri dish after incubation. From the isolation plate of the $10^{-6}$ dilution tube some cells were pricked from one of the four identical colonies obtained and cultured in a nutrient broth medium. The $\mathrm{pH}$ was set precisely to 7.4 through a $\mathrm{pH}$ meter. The liquid culture was cultivated under standard incubation conditions which is at $37^{\circ} \mathrm{C}$ for 24 hours. In this way culturing of the bacterial isolate was done.

\section{Isolation of the Bacterial DNA}

We used a more simplified and convenient method for isolation of the DNA. The protocol involves these steps. $50 \mathrm{ml}$ of culture was 
taken in a fresh eppendorf tube and was centrifuged a 10,000 rpm for 2 minutes in the centrifuge machine. By separating the pellet we added $100 \mu \mathrm{L}$ of TE buffer and $150 \mu \mathrm{L}$ of ST buffer, to lyse the cells. Cell lysis can also be done by physical lysis and enzymatic lysis but we preferred this method in use. The tube was tapped to dissolve these chemicals with pellet. After dissolving the pellet, sample is subjected for incubation by placing it in water bath maintained around $95^{\circ} \mathrm{C}$. Proper mixing is done by inverting the eppendorf tube 6-7 times in every two minutes. Thus, due to high temperature, it degrades proteins and other molecules. After this, cool the tube to room temperature and again centrifuge it at 10,000 rpm for 3 minutes. This is done to renature the nucleic acids which were denatured in the previous step. The supernatant we have in our hand is the DNA of our bacterial isolate. To ensure the availability of only DNA in our tube we go for gel electrophoresis. The $15 \mu \mathrm{L}$ substance was mixed with $2 \mu \mathrm{L}$ of gel loading dye and was loaded in the prepared gel. With the risk of failure involved we took the culture in five vials that's why our loading was also done in five wells of gel electrophoresis chamber. The gel was placed in UV transilluminator for 15 minutes to run. The visibility of orange bands explained the success of isolation of DNA from the bacteria by our rapid protocol.

\section{PCR Amplification of 16s rRNA Gene}

The 16s rRNA coding gene from the DNA was amplified for 25 cycles. The first step here is Pre-Denaturation which involves the separation of entire DNA in single strands. It is done at $95^{\circ} \mathrm{C}$ for 5 minutes. It is followed by Denaturation which is done for $1 \mathrm{~min}$ at $94^{\circ} \mathrm{C}$. In this step only the zone of interest is separated into single strands. Annealing, it involves the addition of primer to its complementary sequence on the strand which here is $16 \mathrm{~s}$ rRNA gene. It was carried at $52^{\circ} \mathrm{C}$ just for 1 minute in each cycle. Renaturation was done at $72^{\circ} \mathrm{C}$ for $1 \mathrm{~min}$ in each cycle. The final step of Extension is at $72^{\circ} \mathrm{C}$ for 7 minutes, with the help of DNA polymerase after all the cycles are over. The benefit of using 16sr RNA gene sequencing technique is that though we don't know the sequence of DNA still we can create the primers for PCR amplification. These primers are "Universal Primers". The basic idea for using universal primers is that we know 16s rRNA gene is unique for all different strains but the flanking regions of 16s rRNA gene remains highly conserved over different species.

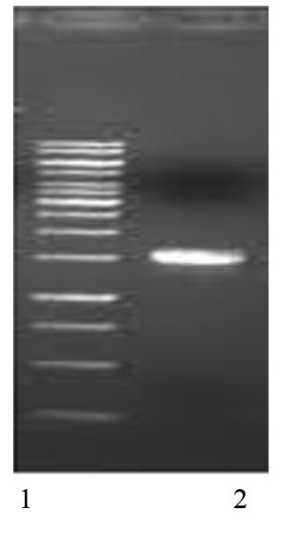

Lane 1 : Marke

Lane 2 : PCR Product

Fig. 1- 16s rRNA PCR Product on $2 \%$ Agarose Gel
So the primer will go and bind to these flanking regions of $16 \mathrm{~s}$ rRNA gene and will enhance the extension of the gene. So we can design primers for novel species containing 16s rRNA gene. The following were the primers used for the amplification and the PCR product size were $1.4 \mathrm{~kb}$.

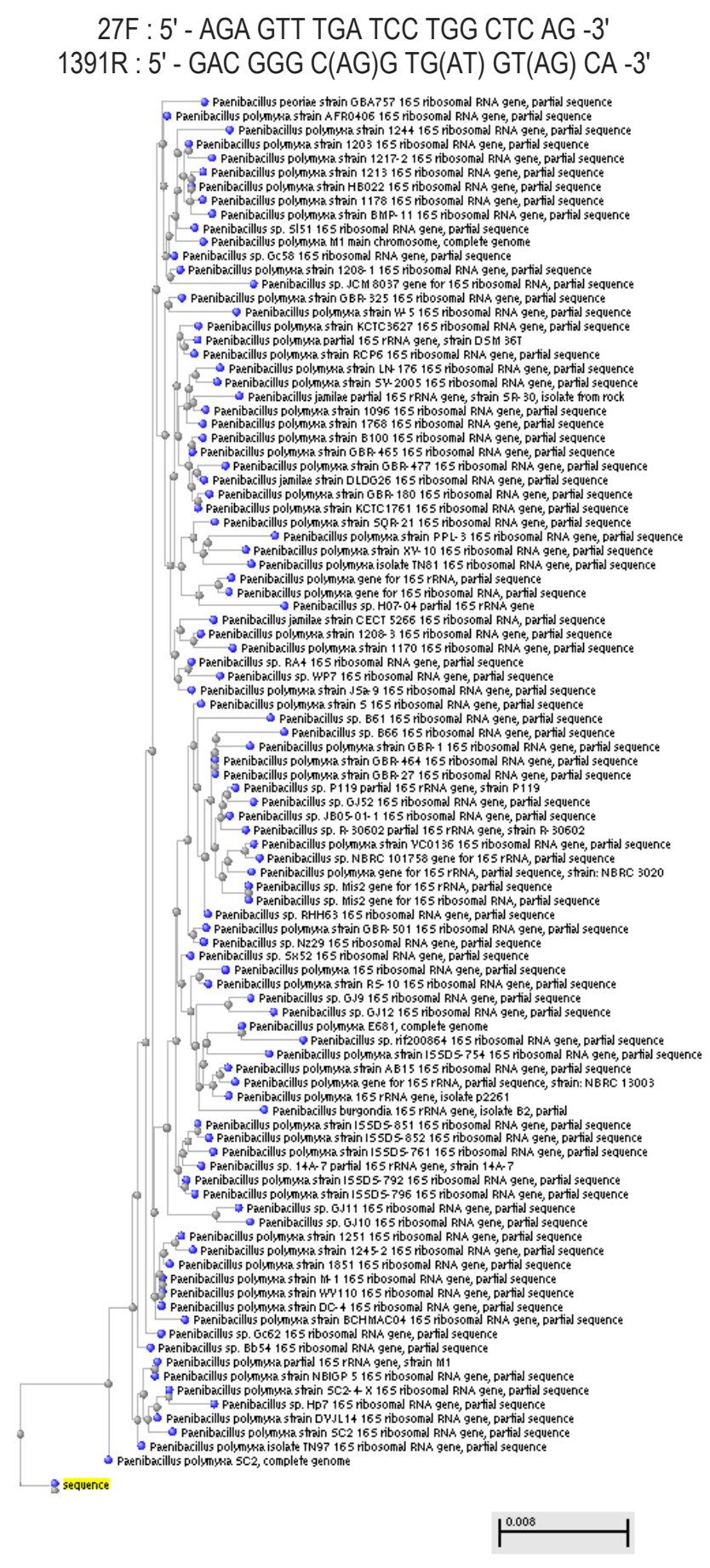

Fig. 2- Phylogenetic affiliation of Paenibacillus polymyxa species EMBS024 against other species of Paenibacillus polymyxa

\section{Purification of the Amplified Product}

After the amplification of the DNA in PCR we took the PCR sample in a fresh vial and added $5 \mu \mathrm{L}$ of $3 \mathrm{M}$ sodium acetate solution 
$(\mathrm{pH}=4.6)$ and $100 \mu \mathrm{L}$ of absolute ethanol in it and mixed it thoroughly. Then we vortexed the vial and left it at $-20^{\circ} \mathrm{C}$ for $30-40$ minutes to precipitate the PCR products. Then it was subjected to centrifugation for 5 minute at $10,000 \mathrm{rpm}$. To the pellet we added $300 \mu \mathrm{L}$ of $70 \%$ ethanol, without mixing, it was again subjected to centrifugation for 5 minutes at $10,000 \mathrm{rpm}$. The produced pellet was air dried until the ethanol effervescence is removed. And lastly the pellet is suspended in $10 \mu \mathrm{L}$ of sterile distilled water.

\section{Sequencing the Product}

The PCR product was sequenced using the ABI Prism. Sequencing reactions were carried out with ABI PRISM Dye Terminator Cycle Sequence Ready Reaction Kit (Applied Biosystems Inc., USA). The novel isolated sequence was deposited in GenBank with accession number JQ004091, maintained by the National Centre for Biotechnology Information (NCBI), at the National Institute of Health $(\mathrm{NIH})$, Rockville, Maryland, USA.

\section{References}

[1] Gibson G.R. and Bruck W. (2009) British journal of nutrition, (90).

[2] Fuller R. (1989) The Journal of Applied Bacteriology, 66(5), 365-78.

[3] Kalliomaki M., Salminen S., Poussa T., Arvilommi H., Kero P., Koskinen P. and Isolauri E. (2001) Probiotics in primary prevention of atopic disease, a randomised placebo-controlled trial.

[4] Rafter J., Bennett M., Caderni G., Clune Y., Hughes R., Karlsson P.C., Klinder A., O'Riordan M., O'Sullivan G.C., PoolZobel B. et al. (2007) Am. J. Clin. Nutr., 85, 488-496.

[5] King C.K., Glass R., Bresee J.S., Duggan C. (2003) Recomm. Rep., 52 (RR -16), 1-16.

[6] Stephen daniells (2007) Probiotics may protect against food poisoning.

[7] Mingchao Ma, Cuicui Wang, Yanqin Ding, Li Li, Delong Shen, Xin Jiang, Dawei Guan, Fengming Cao, Huijun Chen, Ruihua Feng, Xuan Wang, Yifan Ge, Liangtong Yao, Xiaohui Bing, Xiaohong Yang, Jun Li, and Binghai Du. (2011) J. Bacteriol., 193(1), 311-312.

[8] Salme Timmusk, Nina Grantcharova and Gerhart E., Wagner H. (2005) Appl. Environ. Microbiol., 71(11), 7292-7300.

[9] Zengguo He, Duygu Kisla,Liwen Zhang, Chunhua Yuan, Kari B. Green-Church and Ahmed E. Yousef (2007) Appl. Environ. Microbiol., 73(1), 168-178.

[10] Jihyun F. Kim, Haeyoung Jeong, Soo-Young Park, Seong-Bin Kim, Yon Kyoung Park, Soo-Keun Choi, Choong-Min Ryu,Cheol-Goo Hur,Sa-Youl Ghim, Tae Kwang Oh, Jae Jong Kim, Chang Seuk Park, and Seung-Hwan Park. (2010) J. Bacteriol., 192(22), 6103-6104.

[11]Ariza A., Eklöf J.M., Spadiut O., Offen W.A., Roberts S.M., Besenmatter W., Friis E.P., Skjøt M., Wilson K.S., Brumer H., Davies G. (2011) J. Biol. Chem., 286(39), 3890-900.

[12]Lu F., Lu Z., Bie X., Yao Z., Wang Y., Lu Y. and Guo Y. (2010) Thromb Res., 126(5), e349-55.

[13]Karim Naghmouchi, Lyn Paterson, Bob Forster, Tim McAllister, Sam Ohene-Adjei, Djamel Drider, Ron Teather, John Baah. (2011) Arch. Microbiol., 193, 169-177.

[14]Kalpana Devi M., Rasheedha Banu A., Gnanaprabhal G.R.,
Pradeep B.V. and Palaniswamy M. (2008) Indian Journal of Science and Technology, 1(7).

[15]Stenn K.S., Link R., Moellmann G., Madri J., Kuklinska E. Dispase (1989) J. Invest. Dermatol., 93(2), 287-90.

[16]Tezel T.H., Del Priore L.V., Kaplan HJ. (1998) Retina., 18(1), 7-15.

[17]Jill E. Clarridge (2004) Clin. Microbiol. Rev., 17(4), 840-862.

[18]Yi-Wei Tang, Nicole M. Ellis, Marlene K. Hopkins, Douglas H. Smith, Deborah E. Dodge, and David H. (1988) J. Clin. Microbiol., 36(12), 3674-3679.

[19]Michael Janda J. and Sharon L. Abbott. (2007) Journal of Clinical Microbiology, 2761-2764. 